\title{
Expressão da proteína p53 no carcinoma de células escamosas corneal em cães
}

\section{p53 protein expression in corneal squamous cell carcinomas of dogs}

\author{
Lucas Bahdour Cossi ${ }^{1 *}$; Silmara Sanae Sakamoto Lima ${ }^{1}$; Alexandre Lima Andrade ${ }^{2}$
}

\section{Resumo}

As neoplasias oculares representam uma crescente preocupação na oftalmologia veterinária. $\mathrm{O}$ carcinoma de células escamosas corneal é raro em cães e, por isso, pouco estudado. Pesquisas investigando os mecanismos da carcinogênese que contribuem para o desenvolvimento do carcinoma de células escamosas (CCE) ocular em cães são infrequentes. No presente trabalho, teve-se por objetivo identificar, por imunoistoquímica, a expressão da proteína p53 no carcinoma de células escamosas corneal espontâneo de cães. Foram utilizados cinco casos de CCE corneal e um caso de ceratite actínica. Os cortes foram obtidos a partir dos blocos de parafina e submetidos à análise anatomopatológica e imunoistoquímica. Do total de seis amostras, todas apresentaram imunomarcação para citoqueratina e para a proteína p53. Conclui-se que a imunorreatividade da proteína p53 pela imunoistoquímica foi presente nos CCE corneal de cães contribuindo para sua carcinogênese, mas não fornece indicadores de prognóstico em casos de $\mathrm{CCE}$ da córnea em cães; e pode existir forte relação da exposição à radiação solar com a possível mutação do gene TP53.

Palavras-chave: Cão, córnea, imunoistoquímica, neoplasia

\begin{abstract}
Ocular tumors play an increasing concern in veterinary ophthalmology. Corneal squamous cell carcinoma is unfrequent in dogs, and by this way it has little studies. Studies that investigated the carcinogenesis mechanisms wich could help to the development of ocular squamous cell carcinoma (SCC) in dog are rare. The aim of this work was to identify by immunohistochemical techniques, the p53 protein expression in the spontaneous dog corneal SCC. For this work, were used five cases of corneal SCC and one case of actinic keratitis. The sections were obtained from paraffin-wax blocks and submitted to histopathological and immunohistochemical analysis. All the six samples showed immunolabeling to cytokeratin and p53 protein. These results support the conclusions that the immunoreactivity of p53 protein by immunohistochemistry is present in canine corneal SCC suppporting its role in carcinogenesis of this tumor, but not provides prognostic indicators in cases of SCC corneal in dog; and can be a association of exposure to solar radiation with the possible mutation of the TP53 gene.
\end{abstract}

Key words: Dog, cornea, immunohistochemistry, tumors

\footnotetext{
1 Discentes, Universidade Estadual Paulista, UNESP, Araçatuba, SP. E-mail: lucascossi@yahoo.com.br; sanae@ig.com.br

2 Prof., UNESP, Araçatuba, SP. E-mail: landrade@fmva.unesp.br

* Autor para correspondência
} 


\section{Introdução}

Há uma variedade de neoplasias que afetam a conjuntiva e os anexos oculares de animais domésticos, mas elas são relativamente raras (DUBIELZIG, 1990; MONTIANI-FERREIRA et al., 2009). Os tumores oculares podem ser primários ou secundários; estes últimos constituem-se em metástases de neoplasias não oculares. Já os de origem primária são pouco frequentes e, por isso, seu comportamento ainda é pouco conhecido. Isso é agravado pelo fato de que o diagnóstico precoce não impede, às vezes, na perda do olho, pois a enucleação ainda é o tratamento de escolha, apesar de novas modalidades de tratamento serem descritas (WERNER et al., 1998).

As neoplasias oculares (extra e intrabulbares) representam uma crescente preocupação na oftalmologia veterinária (MONTIANI-FERREIRA et al., 2009). Em quaisquer circunstâncias, seus efeitos sobre a função ocular e a visão podem ser drásticos (MONTIANI-FERREIRA et al., 2009; WERNER et al., 1998).

O olho é um local incomum para metástase de neoplasias originadas de outros locais, mas a possibilidade de doença ocular causada pela disseminação hematógena para este tecido deve ser considerada. Qualquer exame ocular deve ser combinado com um exame físico completo e minucioso (DUBIELZIG, 1990). O carcinoma de células escamosas (CCE) ou carcinoma espinocelular é uma doença neoplásica maligna das células epiteliais escamosas que comumente afeta animais de peles despigmentadas (KARASAWA; MATSUDA; TANAKA, 2008).

As neoplasias da córnea são raras e, quase sempre, representam uma extensão secundária de lesões com foco primário em outro segmento do bulbo do olho; geralmente resulta do crescimento de uma massa conjuntival ou limbar (LATIMER; KASWAN; SUNDBERG, 1987; WARD; LATIMER; ASKREN, 1992). No que se refere aos CCE no bulbo do olho, ele surge do epitélio conjuntival do limbo, da conjuntiva bulbar, da membrana nictitante, ou da epiderme das pálpebras, ocorrendo com maior frequência no gato e em outras espécies como bovinos, equinos, homem e, raramente, tem sido relatado em cães (KAPS et al., 2005; KARASAWA; MATSUDA; TANAKA, 2008; LATIMER; KASWAN; SUNDBERG, 1987; MONTIANI-FERREIRA et al., 2008; WARD; LATIMER; ASKREN, 1992; WERNER et al., 1998). A sua localização em cães certamente não é comum e um diagnóstico impreciso pode atrasar potencialmente o tratamento e aumentar a gravidade do quadro (MONTIANI-FERREIRA et al., 2008).

Morfologicamente, o CCE corneal apresenta uma invasão direta e profunda no estroma da córnea com penetração até próxima da membrana de Descemet. Esta, em contraste com a membrana basal da córnea parece ser bem resistente à invasão neoplásica, e a penetração da membrana de Descemet pelo carcinoma nunca foi observada. Quando originado do limbo, o CCE pode se infiltrar mais profundamente, e se desenvolver junto à membrana de Descemet, infiltrando-se no trabeculado, ângulo iridocorneal do olho, progredindo para o interior, por dentro do músculo ciliar, processo ciliar ou íris (KAPS et al., 2005). Apesar de metástases do CCE ocular serem raras, elas podem ocorrer em linfonodos regionais da cabeça; e a invasão local agressiva pode se propagar pelos tecidos adjacentes (WARD; LATIMER; ASKREN, 1992).

Poucos estudos investigando os mecanismos de carcinogênese que contribuem para o desenvolvimento do CCE em cães e gatos foram conduzidos (WEBB et al., 2009). A etiopatogênese do tumor de células escamosas, particularmente o CCEs da região ocular e periocular não é completamente compreendida, mas algumas causas potenciais podem ser relacionadas: trauma contínuo, agentes virais, fatores hormonais, fatores genéticos e imunológicos, a falta de pigmentação nos tecidos perioculares, irritação crônica da superfície ocular, assim como a ceratoconjuntivite seca (CCS) e ceratite pigmentar, e a exposição 
crônica à radiação solar, sendo esta última o agente carcinogênico mais plausível (KAPS et al., 2005; MONTIANI-FERREIRA et al., 2008; WEBB et al., 2009). A aparência clínica da neoplasia ocular varia de modo considerável dependendo do tecido envolvido. Clinicamente, observa-se uma variedade de sinais clínicos no tecido afetado ou nas estruturas adjacentes. É observado opacidade dos meios oculares, desconforto, mudança na forma do bulbo ocular, e em muitos casos, o animal apresenta-se com uma "massa" visível, que pode se apresentar de algumas formas: lesão superficial, lesão ulcerada, proliferativa e elevada, crescimento em forma de "couve flor" (Figura 1A). Estes sinais, com frequência, são os motivos que fazem com que os proprietários levem o paciente ao médico veterinário (MONTIANI-FERREIRA et al., 2009; WEBB et al., 2009).

Figura 1. Foto do caso representado pela amostra 1 apresentando CCE corneal axial (A). Fotomicrografia do histopatológico da mesma amostra, $\mathrm{HE}, 4 \mathrm{x}(\mathrm{B})$.

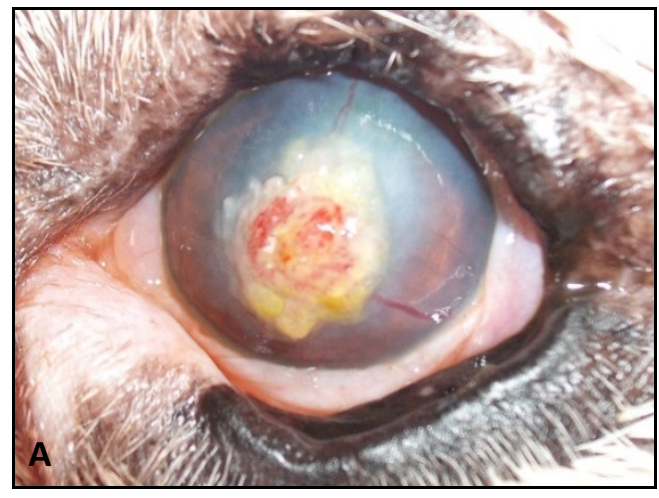

Fonte: Elaboração dos autores.

O diagnóstico precoce do CCE é essencial para uma intervenção terapêutica adequada, que pode resultar no controle por um longo tempo ou a cura definitiva. Pode-se suspeitar do CCE baseado na aparência da lesão e localização, mas o diagnóstico definitivo requer exame microscópico do tecido envolvido (WEBB et al., 2009). A córnea e a conjuntiva são tecidos de fácil acesso, o que possibilita um exame detalhado, além da utilização de técnicas para obtenção de material para exame morfológico, que possam contribuir para o diagnóstico. Um exame clínico minucioso aliado aos procedimentos diagnósticos é imprescindível para determinar natureza, origem, localização e extensão da neoplasia ocular (MONTIANI-FERREIRA et al., 2009).

$\mathrm{O}$ uso da técnica de imunoistoquímica em patologia veterinária tem sido limitado devido à

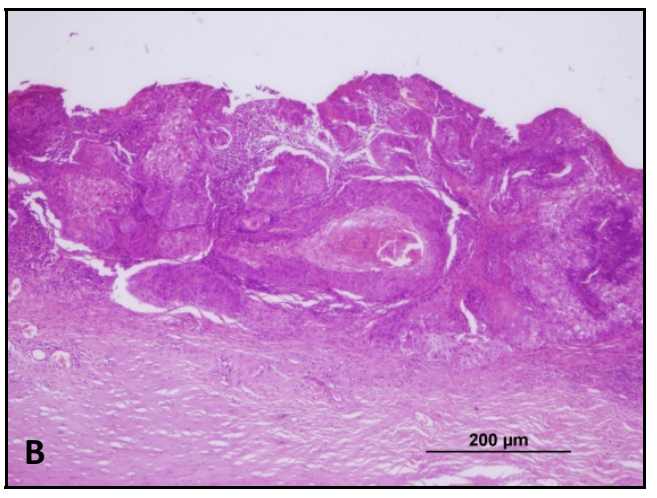

falta de anticorpos contra os tecidos animais, no entanto, podem ser utilizados os anticorpos que apresentam reatividade cruzada entre antígenos humanos e animais de laboratório e, juntamente com outros exames (citologia e histologia), contribuem para o diagnóstico definitivo e preciso desses tumores (TEIXEIRA et al., 2011). Ainda assim, o estudo da imunorreatividade de proteínas no câncer tem se revelado importante ferramenta de trabalho na rotina diagnóstica e de pesquisa. A imunoistoquímica tornou-se uma das técnicas mais utilizadas em laboratórios de diagnóstico e de pesquisa. Atualmente, as tecnologias em genética molecular têm facilitado os estudos dos genes, fornecendo maior conhecimento dos mecanismos etiológicos.

A subversão molecular da morte celular é reconhecida como o principal contribuinte para 
o desenvolvimento e progressão do câncer. A proteína p53 supressora de tumores, que tem um fundamental papel no controle do crescimento e neoplasias, tem sido uma das proteínas mais extensivamente estudadas nos últimos anos. Esta proteína está entre as mais comumente alteradas no câncer humano e o gene TP53 é considerado como um dos genes mutados mais associado ao desenvolvimento de câncer. O supressor de tumor p53 é uma proteína multifuncional que exerce uma variedade de efeitos diferentes, e desempenha um papel central na regulação do ciclo celular normal. Essa proteína medeia funções críticas dentro das células, incluindo a resposta ao estresse genotóxico, senescência, diferenciação e morte celular. A perda de função p53 pode resultar em taxas maiores de proliferação celular, resistência a estímulos de morte celular, instabilidade genômica e metástase. Esta informação permite a concepção de agentes terapêuticos para as proteínas alvo, incluindo p53. A p53 é importante para garantir a estabilidade e integridade do genoma de células normais (CHARI et al., 2009).

Atualmente, a p53 é conhecida por desempenhar um papel fundamental em praticamente todos os tipos de cânceres humanos, e a mutação ou perda do gene TP53 pode ser identificada em mais de $50 \%$ de todos os casos de câncer humano em todo o mundo (BAI; ZHU, 2006; CHARI et al., 2009), o que implica que células cancerosas mantêm a viabilidade através da redução da atividade biológica de p53. Isso enfatiza o papel central da via p53 na regulação de crescimento e sobrevivência celulares. Além disso, as condições da p53 de um tumor pode ter uma forte influência sobre a sensibilidade ao uso de fármacos anti-cancerígenos e radioterapia. P53 é, portanto, um importante marcador clínico e alvo terapêutico. Acredita-se que mutações do gene TP53 são as alterações genéticas mais comuns em neoplasias em cães, entretanto pouco se sabe sobre ele e suas mutações. No caso de lesões por agentes físicos, químicos ou biológicos, é função da p53, através de uma cascata de reações, impedir que esta célula entre em processo de mitose e complete a divisão celular. Assim, dois caminhos podem ser seguidos: a correção da mutação através da ativação da proteína de reparo ou a indução a apoptose, prevenindo, assim, que ocorra a proliferação de células com o DNA mutado (ARRUDA et al., 2008; CASTAÑEDA et al., 2007).

A radiação ultravioleta (UV) é um carcinógeno completo em que não apenas inicia a oncogênese através da indução de mutações no gene supressor de tumor p53, mas também promove o desenvolvimento do tumor (MELNIKOVA et al., 2005), pois um dos principais alvos da radiação UV é o gene TP53. Ele codifica para uma fosfoproteína nuclear de $53 \mathrm{kd}$ que funciona como um regulador do crescimento e proliferação celular (TEIFKE; LÖHR, 1996). Como um promotor de tumores, a radiação UV induz à proliferação celular, estimulando a produção de vários fatores de crescimento e citocinas, bem como a ativação de seus receptores. Como com outros agentes cancerígenos, a radiação UV causa mutação em oncogenes e genes supressores de tumores, e mutações específicas de p53 foram detectadas no carcinomas de células escamosas cutâneas induzido pela luz UV (MELNIKOVA et al., 2005).

Apesar de sua importância, há raros relatos sobre a detecção de p53 no CCEs ocular nos animais domésticos (TEIFKE; LOHR, 1996; SIRONI et al., 1999), sendo raro os relatos dessa proteína especificamente em CCEs corneal (MONTIANIFERREIRA et al., 2008).

Devido a escassez de trabalhos na medicina e medicina veterinária sobre os estudos da expressão dos genes e seus produtos envolvidos do desenvolvimento do carcinoma de células escamosas corneal de cães, propõe-se analisar tais enfoques, uma vez que há deficiência de trabalhos versando sobre a expressão deste marcador na literatura consultada. Acredita-se que o estudo abordando esse tema possa trazer contribuição significante no que tange ao prognóstico e terapêutica do CCE corneal em cães, cuja ocorrência tem sido relevante nos últimos anos. 
Este estudo teve por objetivo avaliar a imunoexpressão da proteína p53 em CCE corneal espontâneo de cães visando investigar sua disfunção no desenvolvimento desta neoplasia.

\section{Material e Métodos}

\section{Amostras}

As amostras estudadas foram obtidas junto ao Serviço de Oftalmologia Veterinária do Centro Universitário de Rio Preto, situado na cidade de São José do Rio Preto-SP, onde foram selecionados seis casos, sendo cinco com diagnóstico de carcinoma de células escamosas corneal e um com diagnóstico de ceratite actínica, no período de três anos (20092011). As amostras foram procedentes de casos clínicos em que os animais foram submetidos aos procedimentos cirúrgicos de ceratectomia lamelar superficial ou enucleação/exenteração dos bulbos oculares envolvidos. Foramcolhidos fragmentos para a análise anatomopatológica e imunoistoquímica para identificação da proteína p53. Para tal, dos blocos parafinados, foram obtidos cortes em secções de três micrômetros $(3 \mu \mathrm{m})$ e colocados em lâminas de vidro, submetidos à coloração de H.E, e pela técnica de imunoistoquímica.

\section{Avaliação anatomopatológica}

Os fragmentos para análise anatomopatológica foram provenientes de peças cirúrgicas que foram fixadas em formol 10\% tamponado por no mínimo 72 horas e, posteriormente, incluídos em parafina. Dos blocos parafinizados, foram obtidos fragmentos de $3 \mu \mathrm{m}$, que foram corados rotineiramente pela coloração de H.E. (Hematoxilina ${ }^{3}$ e Eosina ${ }^{4}$ ) e analisados por microscopia de luz, sendo foto documentadas posteriormente.

\footnotetext{
${ }^{3}$ Eosin Y (2',4',5',7'-tetrabromofluorescein)- C20H8Br4O5, Sigma Chemical CO. St Louis, EUA

4 Hematoxilina (C16H14O6, PM 302,29). Cromato Produtos Químicos LTDA. Indústria Brasileira. Rua Goioerê, 01, Diadema/SP
}

\section{Imunoistoquímica}

Inicialmente, realizou-se a desparafinização do tecido em xilol, à temperatura ambiente por 30 minutos. A hidratação dos cortes foi obtida utilizando-se concentrações decrescentes de álcool. A recuperação antigênica pelo calor foi realizada em forno microondas com solução de citrato $10 \mathrm{~mL}$ $(\mathrm{pH}=6.0)(2,1 \mathrm{~g}$ de ácido cítrico monohidratada diluídos em $1000 \mathrm{~mL}$ de água destilada) em duas etapas de fervura de 5 minutos cada, deixando-se o material resfriar em temperatura ambiente. As lâminas foram lavadas em água corrente e, em seguida, procedeu-se o bloqueio da peroxidase endógena com uma solução de $100 \mathrm{~mL}$ de água oxigenada (20V) diluída em $100 \mathrm{~mL}$ de metanol, durante 30 minutos. Na sequência, as lâminas foram incubadas com o anticorpo primário (anticitoqueratina e anti-p53, SIGMA-ALDRICH ${ }^{\circledR}$ ), por 18 horas a uma temperatura de $4^{\circ} \mathrm{C}$ em câmara úmida e, como controle negativo, não se utilizou o anticorpo primário sobre os tecidos. Ato contínuo, as lâminas foram lavadas em solução tampão PBS $(\mathrm{pH}=7,4)$. A incubação com o "kit” LSAB $\left(\right.$ Dako $\left.^{\circledR}\right)$, que contempla o anticorpo secundário, ocorreu durante 30 minutos em câmara úmida. Em seguida, as lâminas foram submetidas à passagem em solução tampão. A diluição do anticorpo primário para as duas proteínas foi 1:100 em diluente próprio, cuja diluição foi padronizada previamente. A revelação foi conduzida utilizando-se o cromógeno diaminobenzidina (DAB), com sucessivas lavagens em solução tampão, água corrente e água destilada. Por fim, foi realizada a contra-coloração com Hematoxilina de Harrys $\left(\right.$ Dako $^{\circledR}$ ), 5,0 mL por lâmina e lavagem em água destilada. Os cortes foram desidratados em lavagens crescentes de álcool e xilol e, posteriormente, montados em resina sintética. Os cortes histológicos foram submetidos à imunomarcação para citoqueratina (PCK-26, SIGMA-ALDRICH ${ }^{\circledR}$ ) para confirmação da origem epitelial dos tumores. 


\section{Avaliação microscópica}

Os cortes histológicos correspondentes ao procedimento de imunoistoquímica foram analisadas em microscopia de luz e, em seguida, fotodocumentadas em microscópio Olympus BX 60 (DP 71). Os dados foram analisados por um único avaliador. Na imunoistoquímica, avaliou-se onúmero de células marcadas por campo no microscópio adotando-se dois critérios de classificação em escores, proposto por Sannino e Shousha (1994): 1) quanto à intensidade de marcação: 0 (ausente), 1+ (leve), 2+ (moderado) e 3+ (intenso); e 2) quanto à frequência de marcação: 0 (ausente), $1+(<10 \%$ de marcação celular), $2+(10 \%$ a $30 \%$ de marcação celular), $3+(30 \%$ a $70 \%$ de marcação celular) e $4+$ (> 70\% de marcação celular), considerando-se todo campo de tecido corado.
As lâminas coradas por H.E. foram utilizadas como controle em relação à observação das regiões imunomarcadas pelo anticorpo anti-p53. Como controle negativo, foi utilizada uma das amostras diagnosticadas com $\mathrm{CCE}$ e processada junto às demais lâminas, porém sem incubar o anticorpo primário, substituindo esse por PBS. Como controle positivo, foi utilizada uma amostra positiva de carcinoma mamário obtida de estudos prévios.

\section{Resultados e Discussão}

Do total das seis amostras analisadas, foram diagnosticados cinco casos de carcinoma de células escamosas corneal e um caso de ceratite actínica. $\mathrm{Na}$ Tabela 1, estão apresentadas as características dos cães nas amostras.

Tabela 1. Distribuição das diferentes amostras avaliadas, segundo idade, raça, sexo e diagnóstico histopatológico.

\begin{tabular}{ccccc}
\hline Amostras & Idade (anos) & Raça & Sexo & $\begin{array}{c}\text { Diagnóstico } \\
\text { histopatológico }\end{array}$ \\
\hline $\mathbf{1}$ & 9 & Buldogue inglês & $\mathrm{F}$ & CCE \\
$\mathbf{2}$ & 11 & Boxer & $\mathrm{M}$ & CCE \\
$\mathbf{3}$ & 9 & Weimaraner & $\mathrm{F}$ & CCE \\
$\mathbf{4}$ & 13 & Boxer & $\mathrm{F}$ & CCE \\
$\mathbf{5}$ & 10 & SRD & $\mathrm{F}$ & CCE \\
$\mathbf{6}$ & 7 & Boxer & F & Ceratite actínica \\
\hline
\end{tabular}

Fonte: Elaboração dos autores.

O perfil imunoistoquímico das lesões foi positiva foi observada em todas as amostras dos considerado como positivo quando as células CCEs corneais e na ceratite actínica (Figura 2 B, C apresentavamcoloração acastanhada para o marcador p53. Não foi observada qualquer expressão para a proteína p53 na amostra controle, demonstrando que não há marcação imunoistoquímica quando a proteína não mutante está presente, significando atividade normal da p53. Por outro lado, marcação e D). A p53 esteve expressa com marcação nuclear e citoplasmática em 100\% dos casos incluídos neste estudo (Tabela 2). Os fragmentos de tecido neoplásico apresentaram forte expressão para a citoqueratina PCK-26 confirmando, desta forma, a origem epitelial dos tumores (Figura 2A). 
Tabela 2. Representação gráfica das amostras avaliadas quanto à intensidade e frequência da marcação, segundo os marcadores utilizados.

\begin{tabular}{ccc}
\hline Proteína / & p53 & Citoqueratina \\
Amostras & I $\mathbf{~}$ & + \\
$\mathbf{1}$ & $+1+1$ & + \\
$\mathbf{2}$ & $+2+1$ & + \\
$\mathbf{3}$ & $+1+1$ & + \\
$\mathbf{4}$ & $+3+2$ & + \\
$\mathbf{5}$ & $+1+3$ & + \\
$\mathbf{6}$ & $+2+1$ & + \\
\hline
\end{tabular}

Legenda: I: intensidade, F: frequência, +: positivo/presente.

Fonte: Elaboração dos autores.

Figura 2. Fotomicrografia da imunoexpressão para citoqueratina na amostra 2, 40X, (A). Fotomicrografia da imunoexpressão para a proteína p53 (setas) na amostra 1, 40x, (B); na amostra 4, 40x, (C); e na amostra 5, 20x (D).
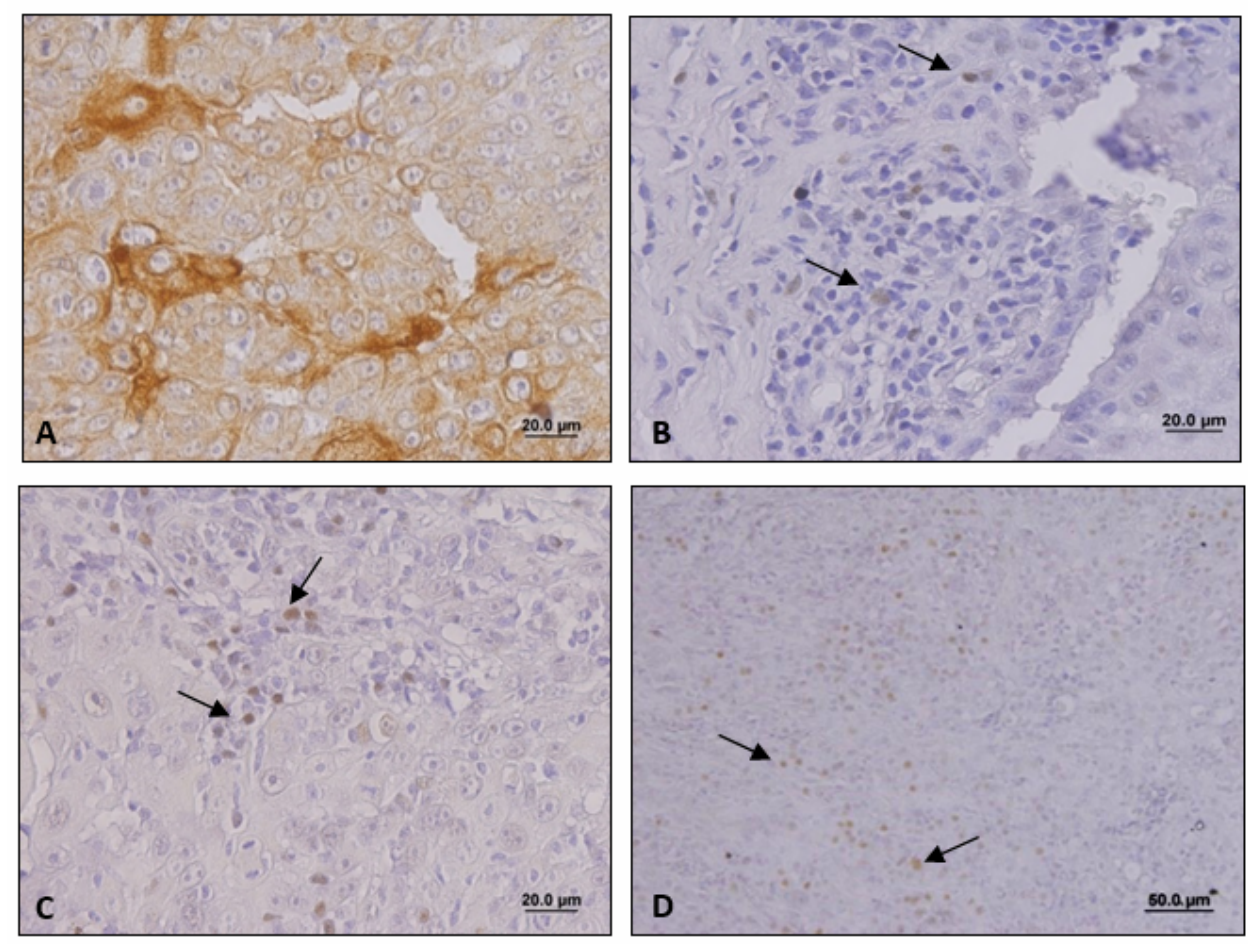

Fonte: Elaboração dos autores.

O diagnóstico das neoplasias oculares pode ser realizado por meio de algumas maneiras, que inclui a histopatologia e também a imunoistoquímica. Aqui foi empregado o diagnóstico histopatológico (Figura 1 B) e a imunoistoquímica, confirmando que tratavam-se de tumores de origem epitelial, na qual foi observada intensa imunoreatividade para a citoqueratina nas amostras.
O presente estudo demonstrou que o acúmulo anormal da proteína p53 foi presente no CCE corneal e na ceratite actínica de cães e sugere que a disfunção desta proteína pode estar envolvida na carcinogênese desta neoplasia.

A expressão aberrante da proteína p53 tem sido descrita em carcinoma de células escamosas conjuntival (SIRONI et al., 1999), e recentemente, 
Lopes et al. (2010) verificaram uma elevada presença e expressão do gene supressor de tumor TP53 e do oncogene c-Myc em tumores de anexos oculares de cães, porém são raros os estudos sobre a função desse gene ou de seu produto em CCE corneal de cães. Da mesma maneira que Montiani-Ferreira et al. (2008) observaram em um CCE corneal canino a forte expressão da p53 por imunoistoquímica, sugerindo que uma mutação do p53 pode ter causado este CCE primário da córnea, nosso estudo também encontrou a expressão desta proteína p53 em todas as cinco amostras. Já Takiyama, Terasaki e Uechi (2010) relataram dois casos de CCE corneal em cães aos quais não expressaram a proteína p53.

A excessiva exposição solar (raios UV) causa danos ao DNA, desempenhando um importante papel no desenvolvimento do CCE. A radiação ultravioleta (UV) é mutagênica para o gene supressor de tumor TP53, e a superexpressão desse gene é provavelmente uma consequência da exposição à radiação ultravioleta (BASTI; MACSAI, 2003; MONTIANI-FERREIRA et al., 2008). A radiação ultravioleta é considerada o principal agente cancerígeno associado com CCE. Os cães, os quais foram utilizados no estudo através de suas amostras, residiam na região de São José do Rio Preto- São Paulo, onde os níveis de raios UV são substancialmente elevados chegando a atingir valores extremos que oscilam entre os graus $12 \mathrm{e}$ 13, em uma escala de zero a 14. A partir do nível 8 na escala, o índice já é considerado muito alto, e ao chegar no grau 11, passa a ser identificado como extremo (INPE, 2013), além de uma temperatura média anual de $23,6^{\circ} \mathrm{C}$ (CEPAGRI, 2013). Esses dados demonstram que a mutação deste gene TP53 pela radiação ultravioleta pode estar envolvida no desenvolvimento do carcinoma de células escamosas em cães. Da mesma maneira, Montiani-
Ferreira et al. (2008) demonstrou que a mutação da proteína p53 encontrada em seu relato de caso, pode ter surgido devido uma mutação do gene TP53 pela radiação ultravioleta, já que a região a qual o cão vivia tinha uma grande índice de radiação solar.

Da mesma forma como citado por Jiang et al. (1999), os resultados aqui reportados apoiam, ainda mais, o conceito de que mutação no gene TP53 pode servir como um marcador precoce do desenvolvimento de carcinoma escamoso de córnea em cães, e que a prevenção de tal mutação, como a restrição à exposição aos raios UV, podem evitar a ocorrência da neoplasia.

A constatação da expressão da p53 na amostra com diagnóstico de ceratite actínica, pode sugerir um evento precoce na progressão da displasia para o carcinoma de células escamosas, apesar de ter sido encontrada em uma única amostra. Justificando essa possibilidade, Coulter, Wolber e Tron (1995), em carcinoma de células escamosas humano, suportam a possibilidade de que a mutação de p53 é um evento molecular observado no início do desenvolvimento desta neoplasia.

O índice mitótico (IM) é uma medida indireta da proliferação celular baseada na quantificação de figuras de mitose em uma amostra histopatológica. Tem sido demonstrado que o IMé um forte preditor do resultado para uma variedade de cânceres humanos e caninos, incluindo o carcinoma de tiróide, carcinoma de mama, sarcomas, entre outros, podendo ser um indicador de prognóstico adicional (ROMANSIK et al., 2007). As amostras aqui utilizadas foram graduadas quanto a sua malignidade, utilizando o índice de mitose como principal método (Tabela 3), porém não foi observada relação entre maior índice mitótico e, portanto, maior malignidade, com uma maior expressão da proteína analisada. 
Tabela 3. Descrição histológica das amostras de carcinoma de células escamosas corneal quanto ao grau de malignidade encontrado.

\begin{tabular}{cl}
\hline Amostras & \multicolumn{1}{c}{ Descrição histológica } \\
\hline $\mathbf{1}$ & Pleomorfismo moderado. Moderado infiltrado inflamatório de permeio. 36 mitoses em 10 campos \\
$\mathbf{2}$ & /40x. \\
$\mathbf{3}$ & Pleomorfismo moderado. Moderado infiltrado inflamatório. 9 mitoses em 10 campos/40x. \\
$\mathbf{4}$ & $\begin{array}{l}\text { Pleomorfismo acentuado. Intenso infiltrado inflamatório. } 21 \text { mitoses em } 10 \text { campos/40x. } \\
\text { células. 13 mitoses em 10 campos/40x. }\end{array}$ \\
$\mathbf{5}$ & $\begin{array}{l}\text { Pleomorfismo acentuado. Intenso infiltrado inflamatório e presença de queratinização individual de } \\
\text { células. } 4 \text { mitoses em 10 campos/40x. }\end{array}$ \\
\hline
\end{tabular}

Fonte: Elaboração dos autores.

Diferentemente de Lopes (2012), que encontrou uma alta expressão das proteínas p53 principalmente nas amostras que foram diagnosticadas com um maior grau de malignidade como os carcinomas, isso não foi observado em nosso trabalho, não podendo relacionar, portanto, a taxa de expressão da proteína p53 com o grau de malignidade tumoral do CCE corneal de cães.

Todos os nossos casos de CCE apresentaram marcação tanto nuclear quanto citoplastmática para p53. A marcação citoplasmática com o anticorpo p53, apesar de não ser específica, é considerada verdadeira por alguns autores. A expressão citoplasmática aumentada da p53 é consequência do sequestro da proteína alterada neste compartimento celular, o que proporciona sua inativação relacionada ao processo neoplásico. A expressão citoplasmática dessa proteína pode estar relacionada a diferenças na regulação do ciclo celular, que implicam no aumento do risco potencial de invasão do tumor. Acredita-se que a marcação citoplasmática é mais frequente do que a literatura informa. Este fato indica uma nova via de sinalização para estes tumores, que pode ser ou não uma forma de transformação como característica de um tumor mais agressivo (TEIXEIRA et al., 2011).

Devido à grande importância da via p53, a compreensão dos mecanismos da função desta proteína é um dos principais desafios, e tal conhecimento pode fornecer novos alvos e abordagens para a manipulação terapêutica desta via no tratamento do câncer. O desafio no futuro será usar o conhecimento de p53 para desenvolver mais estratégias altamente eficazes e novos medicamentos para prevenção e tratamento do câncer com menos efeitos colaterais (BAI; ZHU, 2006).

No entanto, estudos adicionais devem ser realizados para identificar a natureza das proteínas e a presença de mutações genéticas, além de seus envolvimentos no carcinoma de células escamosas corneal.

\section{Conclusão}

Com base nos resultados e, nas condições aqui adotadas, pode-se concluir que a expressão da p53 pela imunoistoquímica foi presente nos CCEs corneal de cães sugerindo a importância desta proteína no desenvolvimento desta neoplasia. A expressão da p53 não apresenta uma tendência para diagnóstico de gravidade do carcinoma escamoso corneal, já que seu grau de expressão não está relacionado com sua agressividade.

Este estudo foi aprovado pelo Comitê de Ética em Experimentação Animal da UNESP-Araçatuba (Protocolo 2013-00808). 


\section{Referências}

ARRUDA, J. T.; BORDIN, B. M.; MIRANDA, L. C. B.; MAIA, D. L. M.; MOURA, K. K. V. O. Proteína p53 e o câncer: controvérsias e esperanças. Estudos, Goiânia, v. 35, n. 1-2, p. 123-141, 2008.

BAI, L.; ZHU, W. p53: Structure, function and therapeutic applications. Journal of Cancer Molecules, Beijing, v. 2, n. 4, p. 141-153, 2006.

BASTI, S.; MACSAI, M. S. Ocular surface squamous neoplasia: a review. Cornea, Chicago, v. 22, n. 7, p. 687704, 2003.

CASTAÑEDA, D. B.; GONZALEZ, P. A.; ORTEGA, M. R. R.; TORRES, H. I. Z. Revision bibliografica de p53: vias de senalizacion y papel en el proceso de carcinogenesis. Revista de Cirurgia e Traumatologia Buco-Maxilo-Facial, Camaragibe, v. 7, n. 2, p. 37-54, 2007.

CENTRO DE PESQUISAS METEREOLÓGICAS E CLIMÁTICAS APLICADAS À AGRICULTURA CEPAGRI. Clima dos municípios paulistas. Campinas: [s.n]. 2013. Disponível em <http://www.cpa.unicamp.br/ outras-informacoes/clima_muni_559.html >. Acesso em: 14 ago. 2013.

CHARI, N. S.; PINAIRE, N. L.; THORPE, L.; MEDEIROS, L. J.; ROUTBORT, M. J.; MCDONNELL, T. J. The p53 tumor suppressor network in cancer and the therapeutic modulation of cell death. Apoptosis, Texas, v. 14, n. 4, p. 336-347, 2009.

COULTER, L. K.; WOLBER, R.; TRON, V. A. Sitespecific comparison of p53 immunostaining in squamous cell carcinomas. Human Pathology, British Columbia, v. 26, n. 5, p. 531-533, 1995.

DUBIELZIG, R. R. Ocular neoplasia in small animals. Veterinary Clinics of North America: Small Animal Practice, Madison, v. 20, n. 3, p .837-848, 1990.

INSTITUTO NACIONAL DE PESQUISAS ESPACIAIS - INPE. Divisão de satélites e sistemas ambientais. índice ultravioleta. São José do Rio Preto: [s.n], 2013. Disponível em $<\mathrm{http}$ ://satelite.cptec.inpe.br/uv/>. Acesso em: 14 ago. 2013.

JIANG, W.; ANANTHASWAMY, H. N.; MULLER, H. K.; KRIPKE, M. L. P53 protects against skin cancer induction by UV-B radiation. Oncogene, Texas, v. 18, n. 29, p. 4247-4253, 1999.

KAPS, S.; RICHTER, M.; PHILIPP, M.; BART, M.; EULE, C.; SPIESS, B. M. Primary invasive ocular squamous cell carcinoma in a horse. Veterinary Ophthalmology, Zurich, v. 8, n. 3, p. 193-97, 2005.
KARASAWA, K.; MATSUDA, H.; TANAKA, A. Superficial keratectomy and topical mitomycin $\mathrm{C}$ as therapy for a corneal squamous cell carcinoma in a dog. Journal of Small Animal Practice, Oxford, v. 49, n. 4, p. 208-210, 2008.

LATIMER, K. S.; KASWAN, R. L.; SUNDBERG, J. P. Corneal squamous cell carcinoma in a dog. Journal of the American Veterinary Medical Association, New York, v. 190, n. 11, p. 1430-1432, 1987.

LOPES, R. A. Imunoexpressão dos marcadores de apoptose em tumores epiteliais de anexos oculares de cães. 2012. Tese (Doutorado em Medicina Veterinária) Faculdade de Medicina Veterinária e Zootecnia. Campus de Botucatu, Universidade Estadual Paulista, Botucatu.

LOPES, R. A.; CARDOSO, T. C.; LUVIZOTTO, M. C. R.; ANDRADE, A. L. Occurrence and expression of p53 suppressor gene and c-Myc oncogene in dog eyelid tumors. Veterinary Ophthalmology, Araçatuba, v. 13, n. 2, p. 69-75, 2010.

MELNIKOVA, V. O.; PACIFICO, A.; CHIMENTI, S.; PERIS, K.; ANANTHASWAMY, H. N. Fate of UVBinduced p53 mutations in SKH-hrl mouse skin after discontinuation of irradiation: relationship to skin cancer development. Oncogene, Houston, v. 24, n. 47, p. 70557063, 2005.

MONTIANI-FERREIRA, F.; KIUPEL, M.; MUZOLON, P.; TRUPPEL, J. Corneal squamous cell carcinoma in a dog: a case report. Veterinary Ophthalmology, Curitiba, v. 11, n. 4, p. 269-272, 2008.

MONTIANI-FERREIRA, F; WOUK, A. F. P. F.; LIMA, A. S.; KLEINER, J. A.; MUZOLON, P. Neoplasias oculares. In: DALECK, C. R.; NARDI, A. B. de; RODASKI, S. Oncologia em cães e gatos. [S.1]: Roca, 2009. cap. 17, p. 293-312.

ROMANSIK, E. M.; REILLY, C. M.; KASS, P. H.; MOORE, P. F.; LONDON, C. A. Mitotic index is predictive for survival for canine cutaneous mast cell tumors. Veterinary Pathology, Columbus, v. 44, n. 3, p. 335-341, 2007.

SANNINO, P.; SHOUSHA, S. Demostration of oestrogen receptors in paraffin wax sections of breast carcinoma using the monoclonal antibody 1D5 and microwave ove processing. Journal of Clinical Pathology, London, v. 47, n. 1, p. 90-92, 1994.

SIRONI, G.; RICCABONI, P.; MERTEL, L.; CAMMARATA, G.; BROOKS, D. E. P53 protein expression in conjunctival squamous cell carcinomas of domestic animals. Veterinary Ophthalmology, Gainesville, v. 2, n. 4, p. 227-231, 1999. 
TAKIYAMA, N.; TERASAKI, E.; UECHI, M. Corneal squamous cell carcinoma in two dogs. Veterinary Ophthalmology, Kanagawa, v. 13, n. 4, p. 266-269, 2010.

TEIFKE, J. P.; LÖHR, C. V. Immunohistochemical detection of P53 overexpression in paraffin waxembedded squamous cell carcinomas of cattle, horses, cats and dogs. Journal of Comparative Pathology, Giessen, v. 114, n. 2, p. 205-210, 1996.

TEIXEIRA, M. J. D.; SOBRAL, A. P. V.; ABREUELIMA, M. C.; MAIA, F. C. L.; CHRISTILIS, M.; SOUZA, D. M. B.; ADRIÃO, M.; WISCHRAL, A. Avaliação da superexpressão da proteína p53 e das mutações no éxon 8 do gene TP53 em carcinomas mamários caninos e glândulas normais. Pesquisa Veterinária Brasileira, Seropédica, v. 31, n. 6, p. 521-526, 2011.
WARD, D. A.; LATIMER, K. S.; ASKREN, R. M. Squamous cell carcinoma of the corneoscleral limbus in a dog. Journal of the American Veterinary Medical Association, New York, v. 200, n. 10, p. 1503-1506, 1992.

WEBB, J. L.; BURNS, R. E.; BROWN, H. M.; BRUCE, E. L.; KOSAREK, C. E. Squamous cell carcinoma. Compendium: Continuing Education for Veterinarians, Georgia, v. 31, n. 3, p. 133-142, 2009.

WERNER, P. R.; CHIQUITO, M.; PACHALY, J. R.; FERREIRA, F. M. Neoplasias oculares diagnosticadas em animais do sul do Paraná, Brasil. Arquivo de Ciências Veterinárias e Zoologia da UNIPAR, Curitiba, v. 1, n. 1, p. 13-21, 1998. 
